\title{
An update to the Milk Allergy in Primary Care guideline
}

\author{
Adam Fox ${ }^{1 *} \mathbb{0}$, Trevor Brown 2 , Joanne Walsh ${ }^{3}$, Carina Venter ${ }^{4}$, Rosan Meyer ${ }^{5}$, Anna Nowak-Wegrzyn 6 , \\ Michael Levin ${ }^{7}$, Hannah Spawls ${ }^{8}$, Jolene Beatson ${ }^{8}$, Marie-Therese Lovis ${ }^{9}$, Mario C. Vieira ${ }^{10,11}$ and David Fleischer ${ }^{4}$
}

\begin{abstract}
The Milk Allergy in Primary (MAP) Care guideline was first published in 2013 in this journal. MAP aimed to provide simple and accessible algorithms for UK clinicians in primary care, detailing all the steps between initial presentation, through diagnosis, management and tolerance development. Despite its UK focus, it soon became clear that MAP was being accessed internationally and thus an updated International Milk Allergy in Primary Care (iMAP) guideline was published in 2017. Both guidelines used existing international consensus guidelines to develop accessible algorithms accompanied by patient information leaflets. In 2018, the guidelines were criticised for 3 distinct reasons: promoting the overdiagnosis of cow's milk allergy (CMA), negatively impacting breastfeeding and the possibility of industry influence on the guidelines. The authors address these criticisms using available evidence and, in the context of this and in consultation with patient groups, members of the General Practice Infant Feeding Network and other infant feeding healthcare leads, have collaboratively produced updated algorithms and an information leaflet to support breastfeeding. We believe IMAP is now closer to its original aim of facilitating early and accurate diagnosis of CMA, whilst minimising, as far as possible, any concerns around overdiagnosis or a risk to breastfeeding rates. We continue to welcome open and constructive engagement about how best to achieve these aims to provide evidencebased, practical guidelines for the primary care practitioner.
\end{abstract}

Keywords: Cow's milk allergy, Guidelines, Food allergy, Diagnosis, MAP, iMAP

The Milk Allergy in Primary Care guideline was first published in 2013 in this journal by five authors [1], four of whom had been involved in the development group of the UK National Institute for Health and Care Excellence (NICE) 2011 clinical guideline on the 'Diagnosis and assessment of food allergy in children and young people in primary care and community settings' [2]. The driver for the development of primary care focussed cow's milk allergy (CMA) guidance was the limitations of the scope of the NICE guideline, which did not include management of food allergy, nor any specific detail relating to the challenges of identifying and diagnosing milk allergy, which can present with diverse clinical symptoms, due to either an underlying IgE or a non-IgE mediated

\footnotetext{
*Correspondence: adam.fox@gstt.nhs.uk

1 Department of Paediatric Allergy, Guys and St Thomas' Hospitals NHS

Foundation Trust, London, UK

Full list of author information is available at the end of the article
}

mechanism. There was good evidence that delay in diagnosis was a common problem for patients, particularly in infants with less severe manifestations of non-IgE mediated milk allergy, and this resulted in a significant [3], unnecessary morbidity and anxiety. This was commonly reported by patients to the authors in their own clinical practice.

MAP aimed to provide simple and accessible algorithms for clinicians in primary care, detailing all the steps between initial presentation, through diagnosis and management as well as later follow up to assess for tolerance development, which is almost always seen in early childhood for those children with non IgE mediated milk allergy [1]. In healthcare environments where there is minimal specialist allergy provision, it remains important that mild-moderate non-IgE mediated CMA can be diagnosed accurately and promptly in the primary care setting where these infants are most likely to present. It was considered that a tool which focussed on the UK primary 
care setting was therefore needed, but soon it became clear that MAP was being accessed internationally, with almost 89,000 accesses to date. This initial guideline was therefore updated in 2017 as International Milk Allergy in Primary Care (iMAP) [4]. Seven further authors, representing five other continents, helped to modify the algorithms such that they could act as a template suitable for local adaptation in different international healthcare settings.

Neither MAP nor iMAP claimed to be the result of new evidence reviews, but instead used the existing international consensus guidelines (such as DRACMA, NIAID, NICE, EAACI, ESPGHAN, BSACI) [5-8] to develop easy to use algorithms accompanied by a range of patient information leaflets to help support healthcare professionals seeing infants with symptoms which may represent CMA. The diagnostic and management steps in MAP/iMAP were entirely consistent with these guidelines, and the list of symptoms of mild to moderate nonIgE mediated CMA largely repeated the symptoms listed from other guidelines to illustrate the range of potential presentations. In practice, whilst the algorithms were widely distributed, these were often used without the important context provided by the accompanying article. Any algorithm has to balance the accessibility brought by brevity with the reduced clinical context, potentially leading to the less nuanced decision-making that this may bring.

\section{A Time for Reflection}

In 2018, the iMAP/MAP guidelines were criticised for 3 distinct reasons which will be considered in turn and could be broadly generalised to any of the available CMA guidelines [9]. It is extremely important to consider how the concerns raised could constructively inform changes to the current iMAP guideline in a way that mitigates any potential risks to best practice. In anticipation of the need for the algorithms to evolve over time, these had been hosted on the Allergy UK (UK National allergy charity) website for ease of access and also for ongoing adaptation of a 'live' version.

The first criticism raised is that iMAP promotes overdiagnosis of CMA by suggesting that a large range of common and non-specific symptoms could represent mild to moderate non-IgE mediated CMA. Dietary changes, such as mothers being advised to exclude milk from their diet as part of a diagnostic elimination diet trial or the prescription of hypoallergenic formulas, could thus be happening unnecessarily due to an over-perception of disease. The evidence cited for this was a dramatic increase in prescriptions for hypoallergenic milk formulas over a 10-year period from 2006 (7 years prior to publication of MAP) to 2016, coupled with an absence of evidence of a meaningful increase in the prevalence of CMA during this period. However, the evidence cited with regards to a lack of change in the prevalence of milk allergy related to the same cohort of children at 2 different time points, rather than 2 distinct groups of infants [9]. There was no consideration that there may be an increase in true prevalence, better recognition of previously undiagnosed CMA, or simply more hypoallergenic formula prescribed because soya formula, which these babies may previously have taken, was no longer considered suitable under 6 months of age, and an alternative was needed. It has also been reported that children with mild to moderate non-IgE mediated CMA may have been wrongly labelled with lactose intolerance, with this happening less commonly as awareness of CMA improved, resulting in more prescriptions for hypoallergenic formula and less for lactose-free formula. Critics also questioned whether the passage of B-lactoglobulin, a cow's milk protein, through the breastmilk of nursing mothers, can occur in high enough concentration to cause symptoms in the milk-allergic infant. However, data does support the existence of a CMA in breastfed infants from a prospective observational study of 1749 infants, with $2.2 \%(n=39)$ fulfilling the criteria of CMA; of these milk allergic infants, 9 (23\%) presented with symptoms whilst exclusively breastfed, representing $0.5 \%$ of the entire sample [10]. In addition, the ß-lactoglobulin levels in breastmilk from mothers consuming cow's milk, which ranges between $0.5-150 \mu \mathrm{g} / \mathrm{L}$, is similar to the residue in extensively hydrolysed formulas where reactions have been well-described [11-15].

Whilst we do not agree that either MAP or other guidelines have driven the increased prescriptions of hypoallergenic formulas, the authors acknowledge that the symptoms of mild to moderate non-IgE mediated CMA do overlap significantly with a large number of completely well infants, and whilst it is not within the gift of physicians to change the symptoms of the diseases that we try to recognise, it is extremely important that patients are protected from unnecessary diagnostic elimination diet trials. In the absence of a reliable test or widely used, validated scoring questionnaire for symptoms, the guideline therefore needs to better highlight the importance of not over-interpreting minor symptoms, especially in exclusively breastfed infants, where the likelihood of symptoms being related to milk is much lower than in formula fed infants [10]. The guideline algorithm (Figs. 1 and 2) have thus been revised to highlight the current prevalence of CMA, the importance of using clinical judgement when interpreting symptoms, weighting those that are multiple, persistent, severe or treatment resistant, and drawing direct attention to the danger of overdiagnosis in this context. 


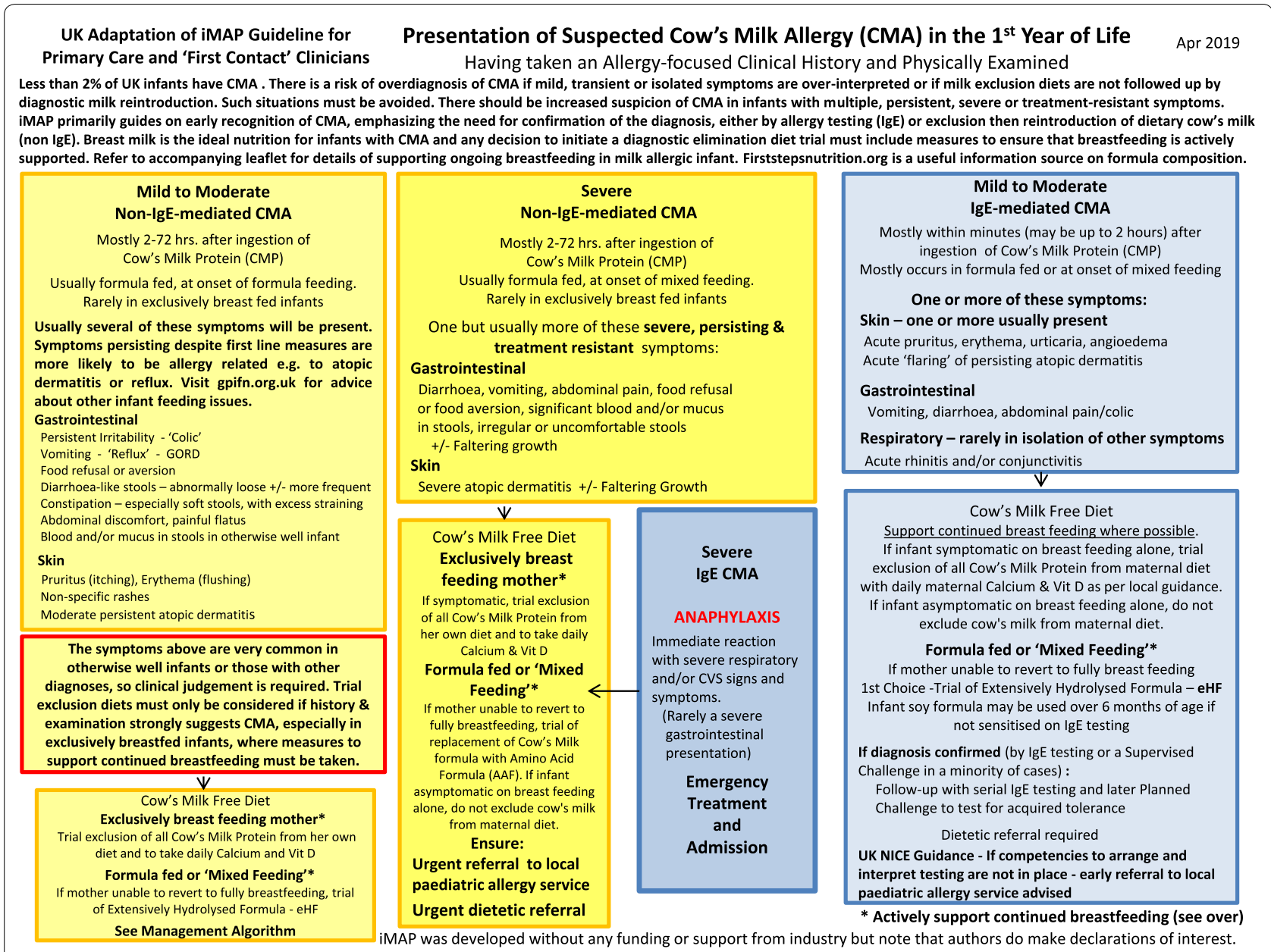

Fig. 1 Presentation of suspected cow's milk allergy (CMA) in the 1st year of Life

In response to the suggestion that guidelines are driving an increase in formula prescription rates, it should be considered that there are no reliable prospective data the authors are aware of to assess if there has been any change of CMA prevalence over the period in question, or any other time period. Some of the most robust, challenge-based data from the Europrevall study estimate a UK prevalence of CMA of $1.28 \%$ at 2 years of age, of which approximately half is due to non-IgE mediated allergy [16]. If there has been an increase in maternal perception of CMA and subsequent overdiagnosis by doctors during the period from 2006 to 2016, it would be unlikely to have been driven by MAP, which was not published until 2013. Indeed, data on the amount spent by the UK NHS on extensively hydrolysed and amino acid formula can be seen to rise sharply from 2003, 10 years prior to publication of MAP [17]. The increase in UK prescriptions for specialist formula also predates the publication of the first CMA focussed guidelines by 4 years [18]. Furthermore, these earlier guidelines had neither a
UK nor primary care focus, did not include any practical algorithms, and were not well known outside the speciality setting; therefore, it is also very unlikely that these could have meaningfully contributed to any systematic, erroneous overdiagnosis.

The issue of over-perception of allergy is very well established and was demonstrated by Venter et al. [19] in a study of infants born in 2001-2002 on the Isle of Wight, when over $33 \%$ of parents reported a food allergy in their child, even though the overwhelming majority were later shown not to have one based upon oral food challenges. In this cohort, over the course of the first 3 years of life, $2.8 \%$ of children were diagnosed with CMA based on DBPCFC, with the majority suffering from mild to moderate non-IgE mediated CMA. The authors do not believe that there is any evidence to support the assertion that CMA guidelines have led to overdiagnosis of CMA, and furthermore believe that the data demonstrating rapidly increasing sales of specialist formula many years prior to the publication of the guidelines, strongly evidence the 


\begin{tabular}{|c|c|c|c|c|c|c|c|c|}
\hline \multicolumn{2}{|c|}{$\begin{array}{l}\text { UK Adaptation of iMAP Guideline for } \\
\text { Primary Care and 'First Contact' Clinicians }\end{array}$} & \multicolumn{6}{|c|}{$\begin{array}{l}\text { Management of Mild to Moderate Non-IgE Cow's Milk Allergy (CMA) } \\
\text { (No initial IgE Skin Prick Tests or Serum Specific IgE Assays necessary) }\end{array}$} & May 2019 \\
\hline \multicolumn{4}{|c|}{ Exclusively Breastfeeding [UK Recommendation $1^{\text {st }} 6$ months] } & \multicolumn{5}{|c|}{ Formula Feeding or 'Mixed Feeding' [Breast and Formula] } \\
\hline \multicolumn{4}{|c|}{$\begin{array}{l}\text { Strict elimination of cow's milk containing foods from maternal diet } \\
\text { Maternal daily supplements of Calcium and Vit } D \text { according to local recommendations } \\
\text { Refer to dietitian - a maternal substitute milk should be advised } \\
\text { An agreed Elimination Trial of up to } 4 \text { weeks - with a minimum of } 2 \text { weeks. } \\
\text { If severe atopic dermatitis or more severe gut symptoms - consider soy/egg avoidance } \\
\text { as well, only with specialist advice } \\
\text { Mothers should be actively supported to continue to breastfeed through this period*. }\end{array}$} & \multicolumn{5}{|c|}{$\begin{array}{l}\text { Strict cow's milk protein free diet } \\
\text { If symptoms only with introduction of cow's milk-based feeds - encourage \& support return } \\
\text { to breastfeeding. Mother can continue to consume cow's milk containing foods in her diet. } \\
\text { If symptoms settle on return to full breast feeding, reconsider diagnosis if symptoms return } \\
\text { on future milk exposure. If symptoms suspected from breastfeeding alone, see Box left. } \\
\text { If any formula feeds are required, advise an eHF. Agree an Elimination Trial of up to } 4 \text { weeks } \\
\text { (minimum of } 2 \text { weeks) and assess improvement. Reintroduction of cow's milk is required } \\
\text { to confirm diagnosis. If weaned - may need advice \& support from dietitian. Only follow } \\
\text { algorithm further in infants receiving eHF/on diagnostic elimination diet trial. } \\
\text { Clear Improvement - neepd to confirm diagnosis } \\
\text { No Clear Improvement }\end{array}$} \\
\hline $\begin{array}{l}\text { But - CMA still suspected: } \\
\text { Refer to local paediatric } \\
\quad \text { allergy service }\end{array}$ & \multicolumn{3}{|c|}{$\begin{array}{l}\text { Home Reintroduction: [NICE Quality Standard] } \\
\text { Mother to revert to normal diet containing cow's } \\
\text { milk foods over period of } 1 \text { week - to be done usually } \\
\text { between 2-4 weeks of starting Elimination Trial }\end{array}$} & \multicolumn{3}{|c|}{$\begin{array}{l}\text { Home Reintroduction: [NICE Quality Standard] } \\
\text { Using cow's milk formula } \\
\text { To be done usually between 2-4 weeks of starting } \\
\text { Elimination Trial. Refer to iMAP reintroduction leaflet. }\end{array}$} & \multirow{3}{*}{\multicolumn{2}{|c|}{$\begin{array}{l}\text { But - CMA still suspected: } \\
\text { Consider initiating a trial of } \\
\text { an Amino Acid Formula } \\
\text { (AAF) } \\
\text { Refer to local paediatric } \\
\text { allergy service }\end{array}$}} \\
\hline $\begin{array}{l}\text { Consider excluding other } \\
\text { maternal foods eg soy, egg }\end{array}$ & & $\downarrow$ & $\downarrow$ & $\downarrow$ & & & & \\
\hline only with specialist advice & \multicolumn{2}{|c|}{$\begin{array}{l}\text { No return of symptoms } \\
\text { NOT CMA - normal feeding }\end{array}$} & $\begin{array}{l}\text { eturn of } \\
\text { mptoms } \\
\end{array}$ & $\begin{array}{l}\text { Return of } \\
\text { symptoms }\end{array}$ & $\begin{array}{l}\text { No re } \\
\text { NOT CI }\end{array}$ & $\begin{array}{l}\text { otoms } \\
\text { feeding }\end{array}$ & & \\
\hline $\begin{array}{l}\text { CMA no longer suspected: } \\
\text { Return to usual maternal diet } \\
\text { Consider referral to local } \\
\text { general paediatric service if } \\
\text { symptoms persist. Visit } \\
\text { gpifn.org.uk for advice about } \\
\text { other infant feeding issues. }\end{array}$ & $\begin{array}{l}\text { Symptoms } \\
\text { do not } \\
\text { settle }\end{array}$ & \multicolumn{2}{|c|}{$\begin{array}{l}\text { Exclude cow's milk containing } \\
\text { foods from maternal diet again } \\
\text { If symptoms clearly improve: } \\
\text { CMA NOW CONFIRMED } \\
\text { If top-up formula feeds should later } \\
\text { be needed - eHF may well be } \\
\text { tolerated. If not - replace with AAF }\end{array}$} & \multicolumn{2}{|c|}{$\begin{array}{l}\text { Support breastfeeding or if } \\
\text { not possible, return to eHF again } \\
\text { If symptoms clearly improve: } \\
\text { CMA NOW CONFIRMED } \\
\text { Ensure support of dietitian }\end{array}$} & $\begin{array}{l}\text { Symptoms } \\
\text { do not } \\
\text { settle }\end{array}$ & \multicolumn{2}{|c|}{$\begin{array}{l}\text { CMA no longer suspected: } \\
\text { Unrestricted diet again } \\
\text { Consider referral to local } \\
\text { general paediatric service if } \\
\text { symptoms persist }\end{array}$} \\
\hline \multicolumn{2}{|c|}{$\begin{array}{l}\text { As likelihood of sufficient cow's milk protein } \\
\text { passage into breast milk to trigger reactions } \\
\text { is low, in breast fed cases, complete milk } \\
\text { exclusion may not be required. }\end{array}$} & \multicolumn{7}{|c|}{$\begin{array}{l}\text { Cow's milk free diet until 9-12 months of age and for at least } 6 \text { months - with support of dietitian } \\
\text { A planned Reintroduction or Supervised Challenge is then needed to determine if tolerance has been acquired } \\
\text { Performing a Reintroduction versus a Supervised Challenge is dependent on the answer to the question: } \\
\text { Does the child have Current Atopic Dermatitis or ANY history at ANY time of immediate onset symptoms? }\end{array}$} \\
\hline \multirow{2}{*}{\multicolumn{3}{|c|}{$\begin{array}{l}\text { No Current Atopic Dermatitis } \\
\text { And no history at any time of immediate onset symptoms } \\
\text { (No need to check Serum Specific IgE or perform Skin Prick Test) } \\
\text { Reintroduction at Home - using a MILK LADDER } \\
\text { To test for Acquired Tolerance }\end{array}$}} & \multirow{2}{*}{\multicolumn{2}{|c|}{$\begin{array}{l}\text { Current Atopic Dermatitis } \\
\text { Check Serum Specific IgE or } \\
\text { Skin Prick Test to cow's milk }\end{array}$}} & \multicolumn{4}{|c|}{$\begin{array}{l}\text { History of immediate onset symptoms at any time } \\
\text { Serum Specific IgE or Skin Prick Test needed }\end{array}$} \\
\hline & & & & & Liaise with loc & $\begin{array}{l}\text { Negative } \\
\text { llergy Service Re }\end{array}$ & Illenge Te & $\begin{array}{l}\text { ositive or } \\
\text { s not available }\end{array}$ \\
\hline \multicolumn{3}{|c|}{$\begin{array}{c}\text { And still no history at any stage of immediate onset symptoms } \\
\text { Reintroduction at Home - using a MILK LADDER } \\
\text { To test for Acquired Tolerance }\end{array}$} & - Negative & Positive & \multicolumn{4}{|c|}{$\begin{array}{l}\text { Refer to local paediatric allergy service } \\
\text { (A Supervised Challenge may be needed) }\end{array}$} \\
\hline
\end{tabular}

* Breast milk is the ideal nutrition for infants \& hence continued breastfeeding should be actively encouraged as far as is possible. WHO recommends breastfeeding until 2 years and beyond. Mothers should be offered support of local NHS breastfeeding support services \& signposted to further support. Please refer to iMAP patient information leaflet on supporting breast feeding.

Fig. 2 Management of mild to moderate non-lgE cow's milk allergy (CMA)

lack of a causal relationship. The publication of iMAP, which has seen much broader uptake than the initial MAP guideline (reported as used by $16.2 \%$ of a sample of 266 GPs, significantly less than local GP guidelines or GP notebook, but more than the $4.1 \%$ using MAP) [20], in 2017, has been followed by a complete plateau in NHS spending of hypoallergenic formula, and in fact, data from IQVIA show a decline in sales on these formula from $£ 64.54 \mathrm{~m}$ in 2017 to $£ 64.51 \mathrm{~m}$ in 2018 , the year following the release of iMAP. Therefore, the data further refutes the suggestion that MAP or iMAP are contributing to increased hypoallergenic formula sales.

The authors believe that effective education and highquality guidance would work against misdiagnosis (both over and underdiagnosis), and consequently avoid unnecessary morbidity or inappropriate prescriptions [21], by providing information for parents and their doctors, rather than incorrect diagnoses being made through a lack of either knowledge or the correct information being given to families. It is also important to note that in 2003, the UK Department of Health issued guidance relating to the use of soy-based infant formulas [22], at the time the mainstay for infants with CMA, advising that they no longer be used in infants under 6 months because of concerns about phytoestrogen levels. This would provide a plausible explanation for a marked uptake in alternative hypoallergenic formulas without requiring any meaningful increase in the number of infants being diagnosed, and is wholly supported by electronic Prescribing Analysis and Cost (ePACT) data showing a marked decline in prescriptions for soy-based formula for the period 2003-2008, falling from 17,114 prescriptions nationally in October 2003 to 8369 prescriptions in September 2008 [17]. It is also noted that the period from 2003-2016 was a time of exponential growth in social media, where it is well established that parents seek out their healthcare advice, much of which comes from uninformed sources, and is very likely to have driven parental concerns around possible food allergy significantly more than a healthcare professional's guideline. Both of these factors coincide 
with the increase of sales of hypoallergenic formulas seen and may offer a plausible explanation for at least a large component of them, that is consistent with the data available.

It is also important to note that one of the most likely causes of overdiagnosis is misclassification of patients as being allergic, due to failure to conduct a re-challenge to milk after a brief exclusion [23]. Without confirming that symptoms return on reintroduction of milk following a diagnostic elimination diet trial, only a presumptive diagnosis of CMA can be made, and there is a risk that infants whose symptoms in fact resolved spontaneously, and not as a result of milk exclusion, will be wrongly labelled as milk-allergic. We believe that a guideline which emphasizes the need for re-challenge to cow's milk, before a diagnosis can be made, is vital to protect against this risk, given the lack of a reliable test.

A further criticism relates to the risk that the guideline may negatively impact breastfeeding rates. Published data on breastfeeding rates in the UK indicated that only $1 \%$ of mothers still exclusively breastfeed at 6 months of age, as per World Health Organization Guidelines [24]. Although $81 \%$ of mothers start to breastfeed, within one week, half have already started infant formula [25]. The causes of the poor breastfeeding rates in the UK are multi-factorial and clearly have social, cultural and political components, with the lack of healthcare professional support for breastfeeding well described. As highlighted in the UNICEF call to action and the Lancet Breastfeeding Series [26], there are clear public health indications for supporting breastfeeding to be every clinician's responsibility and we were keen to review any area where the iMAP may be felt to undermine this. Breastmilk remains the ideal source of nutrition for the cow's milkallergic infant. There are 2 ways that MAP/iMAP has been criticised with regards to breastfeeding. The first is that by raising the possibility that benign symptoms may be related to CMA, this may encourage mothers to consider excluding milk from their diet unnecessarily, with some concern that being on a restrictive diet could contribute to a decision to stop breastfeeding. The other criticism is that the guideline does not emphasize the importance of breastfeeding enough, especially in the context of infants whose symptoms develop when milkbased infant formula is first introduced. There may be a lost opportunity here to actively encourage mothers to return to breastfeeding, rather than simply exchange the milk-based formula for a hypoallergenic one and simple amendments to the guideline can help to mitigate this risk. We have listened to these concerns, recognised that the importance of breastfeeding could be better highlighted and taken measures in the updated algorithms to do this, actively encouraging guideline users to support mothers to continue breastfeeding where at all possible, and to only consider hypoallergenic formulas if this is not possible. We have also developed a new iMAP patient information leaflet which signposts some of the different resources that can specifically support the breastfeeding diet (Additional file 1). We have consulted both parent groups and breastfeeding support groups with specific reference to both the updated algorithms and the new patient information leaflet.

The final criticism relates to the possibility of industry influence on the guidelines. This has been compounded by the widespread dissemination of the MAP/ iMAP algorithms as part of branded promotional material by infant formula manufacturers. We wish to highlight that MAP/iMAP guidelines were published in an open access publication to ensure free access to this educational resource and thus industry branding of the guideline did not require the agreement of the authors, nor was it within their control. Prior to MAP, most CMA guidelines were developed directly with industry funding. MAP and iMAP received no industry funding at all at any stage of development. However, all of the original authors have declared interests relating to work, predominantly around research funding, educational grants or consultancy, with infant formula manufacturers, similar to other national and international clinical guidelines [1, 4]. Whilst these declarations comply with ethical obligations around transparency, there remains a potential risk of unconscious bias, especially when the guidelines relate to the products from which the companies involved are profiting. Such potential for bias may be mitigated through the peer review process, but one possible further method of managing this concern is to widen the circle of those involved in developing the guidance. To this end, the current iteration of the MAP guideline has received patient input from members of a large, online CMA community, Cow's Milk Protein Allergy Support, members of the General Practice Infant Feeding Network and other infant feeding healthcare leads, none of whom has any industry ties. Their advice, received without payment, has led to this version of the guideline hopefully demonstrating a renewed commitment to helping clinicians to support continued breastfeeding and recognising the public health priority of health care workers doing so.

In developing the new iteration of MAP/iMAP, we have attempted to understand the criticisms and address them directly. This guidance will never be perfect for everyone, but we believe it is now closer to its original aim of facilitating early and accurate diagnosis of CMA, whilst minimising, as far as possible, any concerns around overdiagnosis or a risk to breastfeeding rates. We welcome an open and constructive engagement about how best to achieve these aims to provide evidence-based, practical 
guidelines for the practitioner and where further changes may bring us closer to this. We believe that a collaborative approach to this to be in the best interest of our patients, which is something that we all share (Additional file 1).

\section{Additional files}

Additional file 1. Initial fact sheet for infants with symptoms of a possible mild to moderate non-lgE mediated allergy whilst being exclusively or partly breastfed

\section{Abbreviations}

MAP: Milk Allergy in Primary Care; CMA: cow's milk allergy; UK: United Kingdom; US: United States; EAACI: European Academy of Allergy, Asthma and Clinical Immunology; NICE: National Institute of Health and Care Excellence; BSACl: British Society for Allergy and Clinical Immunology; ESPGHAN: European Society for Paediatric Gastroenterology Hepatology and Nutrition; GPS: general practitioners; iMAP: International version: Milk Allergy in Primary Care; eHFs: extensively hydrolysed formulas; AAF: amino acid-based formula; IgE: immunoglobulin E; DRACMA: Diagnosis and Rationale for Action Against Cow's Milk Allergy; NIAID: National Institute of Allergy and Infectious Diseases; ePACT: Electronic Prescribing Analysis and Cost; DBPCFC: double-blind, placebo-controlled food challenge; NHS: National Health Service; UNICEF: United Nations Children's Fund.

\section{Acknowledgements}

We would like to acknowledge the help of members of the CMPA Support group and other infant feeding experts for reviewing the algorithms and patient information leaflet.

\section{Authors' contributions}

AF, RM, JW, TB, CV led in the revision of the algorithms; RM led the development of the patient information material; AF prepared and edited the manuscript. AF, RM, JW, TB, CV, DF, ML, ANW, MV, HS, JB, MTL helped in development of the algorithms, development of the patient information leaflet and preparation of the manuscript. All authors read and approved the final manuscript.

\section{Funding}

No funding was received for any aspect of this work.

\section{Availability of data and materials}

Data sharing not applicable to this article as no datasets were generated or analysed during the current study.

\section{Ethics approval and consent to participate}

Not applicable

\section{Consent for publication}

Not applicable

\section{Competing interests}

Adam Fox has received research funding from Danone and consultancy and/ or educational lecture fees from Mead Johnson, Nestle, Danone and Abbott. $\mathrm{He}$ is director of KCL Allergy Academy and Trustee of British Society of Allergy \& Clinical Immunology and Allergy UK, which have received corporate sponsorship from infant formula manufacturers. Carina Venter has received educational lecture fees from Mead Johnson, Nestle and Danone. Trevor Brown has received educational lecture fees from Mead Johnson, Danone and Abbott. Rosan Meyer has received research funding from Danone and educational lecture fees from Danone, Mead Johnson, Mead Johnson Scientific Advisory Board for Food Allergy UK, Nestle and Cow and Gate and Abbott. Joanne Walsh has received educational lecture fees from Mead Johnson and Danone and acted as a consultant for educational material for both these companies and also for Abbott and Nestle. Anna Nowak-Wegrzyn has received educational lecture fees from Mead Johnson, Nestle and Danone.David Fleischer has received grant support and lecture fees from Nestle Nutrition Institute and educational lecture fees from Abbott and Nutricia. Michael Levin has received research funding from Cipla, support for educational activities from Cipla and Nutricia and educational lecture fees from Cipla. Mario Vieira has received research funding from Danone and educational lecture fees from Danone, Mead Johnson and Nestle.

\section{Author details}

${ }^{1}$ Department of Paediatric Allergy, Guys and St Thomas' Hospitals NHS Foundation Trust, London, UK. ${ }^{2}$ Paediatric Allergy, Ulster Hospital, Belfast BT16 $1 \mathrm{RH}$, Northern Ireland. ${ }^{3}$ Gurney Surgery, Castle Partnership, 70 Fishergate, Norwich NR3 1SE, UK. ${ }^{4}$ Section of Allergy and Immunology, University of Colorado Denver School of Medicine, Children's Hospital Colorado, 13123 East 16th Avenue, Anschutz Medical Campus, Box B518, Aurora, CO 80045, USA. ${ }^{5}$ Department Paediatrics, Imperial College, London, London W2 1NY, UK. ${ }^{6}$ Jaffe Food Allergy Institute, Icahn School of Medicine at Mount Sinai, New York, NY 10029, USA. ${ }^{7}$ Division of Paediatric Allergy and Asthma, Red Cross War Memorial Children's Hospital, University of Cape Town, Room 516, ICH Building, Cape Town, South Africa. ${ }^{8}$ Cow's Milk Protein Allergy Support Group, 5 Cypress Grove, School Aycliffe, Co Durham DL5 6GP, UK. ${ }^{9}$ The Wall House Surgery, Yorke Road, Reigate RH2 9HG, UK. ${ }^{10}$ Center for Pediatric Gastroenterology, Hospital Pequeno Príncipe, Curitiba, Brazil. ${ }^{11}$ Department of Pediatrics, Pontifical Catholic University of Paraná, Curitiba, Brazil.

Received: 19 June 2019 Accepted: 3 August 2019

Published online: 12 August 2019

References

1. Venter C, Brown T, Shah N, Walsh J, Fox AT. Diagnosis and management of non-lgE-mediated cow's milk allergy in infancy - a UK primary care practical guide. Clin Transl Allergy. 2013;3(1):23.

2. National Institute for Clinical E. Diagnosis and assessment of food allergy in children and young people in primary care and community settings. 2011. http://www.nice.org.uk/CG116

3. Sladkevicius E, Nagy E, Lack G, Guest JF. Resource implications and budget impact of managing cow milk allergy in the UK. J Med Econ. 2010;13(1):119-28.

4. Venter C, Brown T, Meyer R, Walsh J, Shah N, Nowak-Wegrzyn A, et al. Better recognition, diagnosis and management of non-lgE-mediated cow's milk allergy in infancy: iMAP-an international interpretation of the MAP (Milk Allergy in Primary Care) guideline. Clin Transl Allergy. 2017;7:26.

5. Fiocchi A, Brozek J, Schunemann H, Bahna SL, von Berg A, Beyer K, et al. World Allergy Organization (WAO) Diagnosis and rationale for action against Cow's Milk Allergy (DRACMA) Guidelines. Pediatr Allergy Immunol. 2010;21(Suppl 21):1-125.

6. Luyt D, Ball H, Makwana N, Green MR, Bravin K, Nasser SM, et al. BSACI guideline for the diagnosis and management of cow's milk allergy. Clin Exp Allergy. 2014;44(5):642-72.

7. Koletzko S, Niggemann B, Arato A, Dias JA, Heuschkel R, Husby S, et al. Diagnostic approach and management of cow's-milk protein allergy in infants and children: ESPGHAN GI committee practical guidelines. J Pediatr Gastroenterol Nutr. 2012;55(2):221-9.

8. Boyce JA, Assa'ad A, Burks AW, Jones SM, Sampson HA, Wood RA, et al. Guidelines for the diagnosis and management of food allergy in the United States: report of the NIAID-sponsored expert panel. J Allergy Clin Immunol. 2010;126(6 Suppl):S1-58.

9. van Tulleken C. Overdiagnosis and industry influence: how cow's milk protein allergy is extending the reach of infant formula manufacturers. BMJ. 2018:363:k5056.

10. Host A, Husby S, Osterballe O. A prospective study of cow's milk allergy in exclusively breast-fed infants. Incidence, pathogenetic role of early inadvertent exposure to cow's milk formula, and characterization of bovine milk protein in human milk. Acta Paediatr Scand. 1988;77(5):663-70.

11. Jarvinen KM, Makinen-Kiljunen S, Suomalainen H. Cow's milk challenge through human milk evokes immune responses in infants with cow's milk allergy. J Pediatr. 1999;135(4):506-12.

12. Kilshaw PJ, Cant AJ. The passage of maternal dietary proteins into human breast milk. Int Arch Allergy Appl Immunol. 1984;75(1):8-15. 
13. Sorva R, Makinen-Kiljunen S, Juntunen-Backman K. Beta-lactoglobulin secretion in human milk varies widely after cow's milk ingestion in mothers of infants with cow's milk allergy. J Allergy Clin Immunol. 1994;93(4):787-92.

14. Rosendal A, Barkholt V. Detection of potentially allergenic material in 12 hydrolyzed milk formulas. J Dairy Sci. 2000;83(10):2200-10.

15. Host A, Halken S. Hypoallergenic formulas-when, to whom and how long: after more than 15 years we know the right indication! Allergy. 2004:59(Suppl 78):45-52.

16. Schoemaker AA, Sprikkelman AB, Grimshaw KE, Roberts G, Grabenhenrich $L$, Rosenfeld $L$, et al. Incidence and natural history of challengeproven cow's milk allergy in European children-EuroPrevall birth cohort Allergy. 2015;70(8):963-72.

17. National Health Services Business Service Authority (NHSBSA) ePACT system. NHS 2003-2008 (cited Data no longer available).

18. Vandenplas Y, Brueton M, Dupont C, Hill DJ, Isolauri E, Koletzko S, et al. Guidelines for the diagnosis and management of cow's milk protein allergy in infants. Arch Dis Child. 2007;92(10):902-8.

19. Venter C, Pereira B, Grundy J, Clayton CB, Roberts G, Higgins B, et al. Incidence of parentally reported and clinically diagnosed food hypersensitivity in the first year of life. J Allergy Clin Immunol. 2006;117(5):1118-24.

20. Choudhury D. Assessment of General practitioner's current approaches to managing Cow's milk protein allergy using existing resources in primary care. London: Imperial College; 2018.
21. Safe M, Chan WH, Leach ST, Sutton L, Lui K, Krishnan U. Widespread use of gastric acid inhibitors in infants: Are they needed? Are they safe? World J Gastrointest Pharmacol Ther. 2016;7(4):531-9.

22. Committee of T. Phytoestrogens and Health. London: Food Standard Agency; 2003.

23. Venter C, Pereira B, Voigt K, Grundy J, Clayton CB, Gant C, et al. Comparison of open and double-blind placebo-controlled food challenges in diagnosis of food hypersensitivity amongst children. J HumNutrDiet. 2007;20(6):565-79.

24. Victora CG, Bahl R, Barros AJ, Franca GV, Horton S, Krasevec J, et al. Breastfeeding in the 21st century: epidemiology, mechanisms, and lifelong effect. Lancet. 2016;387(10017):475-90.

25. UNICEF. Breastfeeding in the UK. New York: UNICEF; 2018

26. Lancet. Lancet Series on Breastfeeding; 2016. https://www.thelancet. com/series/breastfeeding. Accessed July 2019

\section{Publisher's Note}

Springer Nature remains neutral with regard to jurisdictional claims in published maps and institutional affiliations.
Ready to submit your research? Choose BMC and benefit from:

- fast, convenient online submission

- thorough peer review by experienced researchers in your field

- rapid publication on acceptance

- support for research data, including large and complex data types

- gold Open Access which fosters wider collaboration and increased citations

- maximum visibility for your research: over 100M website views per year

At BMC, research is always in progress.

Learn more biomedcentral.com/submissions 